\title{
Gynecological profile of patients undergoing laparoscopy/laparotomy in a tertiary care hospital
}

\author{
Sitalakshmi V. ${ }^{*}$, Alpana Bansal²
}

\begin{abstract}
${ }^{1}$ Department of Obstetrics and Gynecology, Narayana Medical College, Nellore, Andhra Pradesh, India
${ }^{2}$ Department of Obstetrics and Gynecology, Late Baliram Kashyap Memorial Government Medical College, Jagdalpur, Chhattisgarh, India
\end{abstract}

Received: 27 March 2017

Accepted: 26 April 2017

\author{
*Correspondence: \\ Dr. Sitalakshmi V., \\ E-mail: drvsitalakshmi@gmail.com
}

Copyright: (c) the author(s), publisher and licensee Medip Academy. This is an open-access article distributed under the terms of the Creative Commons Attribution Non-Commercial License, which permits unrestricted non-commercial use, distribution, and reproduction in any medium, provided the original work is properly cited.

\begin{abstract}
Background: Laparoscopy is not only used in the elective surgery but also used in the emergency surgery. It is also found to be useful in the acute abdominal emergencies. It is useful in removing any diagnostic doubts. It is also useful in the treatment of diseases. The objective of the study was to study the gynecologic profile of patients undergoing laparoscopy/laparotomy in gynecology department of a tertiary care hospital

Methods: A hospital based cross sectional study was carried out at department of Obstetrics and Gynecology of S. V. Medical College, Tirupati from September 2014 to February 2015, for a period of six months. A total of 36 patients were evaluated for gynecological problems during the study period based on the inclusion and exclusion criteria. They were evaluated for menstrual complaints, chief presenting complaints, clinical diagnosis, scan diagnosis and laparotomy evaluation. Institutional Ethics Committee permission was taken before the start of the study. Informed consent was taken from all patients after explaining them about the nature of the study.

Results: Ovarian cyst was the most common presentation which constituted more than half of the patients $(55.6 \%)$. All patients i.e. $36(100 \%)$ had menorrhagia as the complaint of menstrual irregularity. Out of 9 cases, clinical diagnosis differed in all cases, thus giving zero percent of accuracy for clinical diagnosis. Scan diagnosis matched with laparotomy confirmation in only $3(33.3 \%)$ of cases. One case which was labeled as normal was found to have bilateral functional ovarian cyst on laparotomy confirmation. One case which was labeled as left ovarian cyst was found to have no cyst on laparotomy confirmation.

Conclusions: Thus, laparoscopy is a useful tool for diagnosis and therapeutic accuracy in gynecological disease in routine as well as in emergencies. It is safe, effective, less time consuming, economical and patient friendly.
\end{abstract}

Keywords: Clinical diagnosis, Laparotomy, Ovrian cyst

\section{INTRODUCTION}

In 1974, Semm reported that gynecologic diseases can be managed by laparoscopic approach. Since then there has been a great revolution in the use of devices. Over the period of time, new designs have come up. All this is helping in the more and more use of therapeutic laparoscopic procedures in the management of diseases of gynecologic origin. They are not only safe but also very effective. Thus, laparoscopic procedures have become the method of choice for gynecologists for treatment and management of many gynecologic diseases. ${ }^{1}$ Laparoscopy is not only used in the elective surgery but also used in the emergency surgery. It is also found to be useful in the acute abdominal emergencies. It is useful in removing any diagnostic doubts. It is also useful in the treatment of diseases. ${ }^{2}$ The use of laparoscopy is extended not only in the treatment of 
emergencies of gynecologic origin but also in the diagnosis of acute pelvic pain. It is effective and safe as a treatment of choice in adnexal torsion, dermoid cysts, ovarian cysts and ectopic pregnancy. The advantages of laparoscopic technique are fast recovery and short hospital stay. It also does not affect the future fertility status. In fact, fertility status may be improved by use of it. Even in the first and second trimester of the pregnancy, laparoscopy can be used safely for diagnosing and treating the emergencies of gynecologic diseases. ${ }^{3}$

Previously only for the diagnosis of infertility, chronic pelvic pain, and the sterilization procedures, the laparoscopy was used in gynecology. Slowly over the period of time it was being used in the diagnosis and treatment of ectopic pregnancies. Recently, now it is used for diagnosis and treatment of wide variety of gynecologic conditions.

This not only reduces the operative time, hospital stay of patients but also reduces the risk of infections. The wound is small and acceptable to the patients cosmetically. The patients experience lesser pain. ${ }^{4}$

Now laparotomy has acquired a conventional place in the management of gynecological emergencies like ovarian cystic accident and ectopic pregnancy. Even before the decision of invasive surgery, diagnosis is confirmed by Laparoscopy.

The pelvic organs can be manipulated safely. The certain procedures like hemostasis, intra-abdominal suturing, and irrigation are carried out and there is no need of open surgery. Operative laparoscopy has been enriched by laser and video monitoring. There is a little discomfort to the patient. ${ }^{5}$

Present study was conducted with the objective to study the gynecologic profile of patients undergoing laparoscopy/laparotomy in gynecology department of a tertiary care hospital.

\section{METHODS}

A hospital based cross sectional study was carried out at department of Obstetrics and Gynecology of S. V. Medical College, Tirupati from September 2014 to February 2015, for a period of six months. A total of 36 patients were evaluated for gynecological problems during the study period based on the inclusion and exclusion criteria.

They were evaluated for menstrual complaints, chief presenting complaints, clinical diagnosis, scan diagnosis and laparotomy evaluation. Institutional Ethics Committee permission was taken before the start of the study.

Informed consent was taken from all patients after explaining them about the nature of the study.

\section{Inclusion criteria}

- Patients with chief gynecological complaints presenting to gynecology department

- Patients willing to participate in the study

\section{Exclusion criteria}

- Patients with any other serious ailments

- Patients not willing to participate in the study

- Bed ridden patients

Patients posted for laparotomy/laparoscopy during the study period, eligible for the study as per the inclusion and exclusion criteria of the study, were randomly selected and included in the study. Their chief presenting complaints were noted. Detailed and thorough clinical examination was carried out including per vaginum examination. Based on the history and clinical examination, a clinical diagnosis was formed. Then all the patients were referred to the radiology department for ultrasonography. Based on the sonography reports, their scan diagnosis was noted in the questionnaire. Out of 36 cases, 9 cases were posted for laparoscopy/laparotomy. Then the laparoscopy/laparotomy diagnosis was made. The clinical diagnosis, scan diagnosis and laparoscopy/laparotomy diagnosis was compared and noted. All the data was entered in the pre-designed, pretested, semi structured questionnaire. The data analysis was done using proportions.

\section{RESULTS}

Table 1: Distribution of study subjects as per the pelvic pathology.

\begin{tabular}{|lll|}
\hline Pelvic pathology & Number & $\%$ \\
\hline Fibroids & 12 & 33.3 \\
\hline Pelvic inflammatory disease & 04 & 11.1 \\
\hline Ovarian cyst & 20 & 55.6 \\
\hline Total & 36 & 100 \\
\hline
\end{tabular}

Ovarian cyst was the most common presentation which constituted more than half of the patients (55.6\%). The next most common presentation was fibroids which was present in $12(33.3 \%)$ of patients. While in the present study, only four patients presented with pelvic inflammatory disease.

Table 2: Distribution of study subjects as per their complaints of menstrual irregularities.

\begin{tabular}{|lll|}
\hline Menstrual irregularities & Number & $\%$ \\
\hline Menorrhagia & 36 & 100 \\
\hline Oligomenorrhea & 08 & 22.2 \\
\hline Monometrorrhagia & 04 & 11.1 \\
\hline
\end{tabular}

All patients i.e. $36(100 \%)$ had menorrhagia as the complaint of menstrual irregularity. Oligomenorrhea was seen in $4(11.1 \%)$ of patients. 
Table 3: Distribution of study subjects as per their complaints.

\begin{tabular}{|lll|}
\hline Complaints & Number & $\%$ \\
\hline Mass per abdomen & 09 & 25 \\
\hline Pain abdomen & 10 & 27.8 \\
\hline Menstrual abnormalities & 08 & 22.2 \\
\hline Infertility & 09 & 25 \\
\hline Total & 36 & 100 \\
\hline
\end{tabular}

The most common presenting chief complaint of the patients in the department was pain abdomen in 10 $(27.8 \%)$ of cases followed by mass per abdomen and infertility in $9(25 \%)$ of cases. Remaining $8(22.2 \%)$ of cases presented with menstrual abnormalities.

Table 4: Comparison between Scan diagnosis, clinical diagnosis and laparotomy confirmation in 9 cases.

\begin{tabular}{|c|c|c|}
\hline $\begin{array}{l}\text { Clinical } \\
\text { diagnosis }\end{array}$ & $\begin{array}{l}\text { Scan } \\
\text { diagnosis }\end{array}$ & $\begin{array}{l}\text { Laparotomy } \\
\text { confirmation }\end{array}$ \\
\hline Fibroids & No fibroid & Bilateral cysts \\
\hline TB Endometritis & $\begin{array}{l}\text { Multilocular } \\
\text { cysts }\end{array}$ & 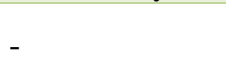 \\
\hline Adenomyosis & Fibroids & Fibroids \\
\hline $\begin{array}{l}\text { Unicornuate } \\
\text { uterus }\end{array}$ & Septate uterus & $\begin{array}{l}\text { Fundal fibroids } \\
\text { with septum in } \\
\text { mid line }\end{array}$ \\
\hline Adenomyosis & $\begin{array}{l}\text { Fibroid, cystic } \\
\text { mass right side }\end{array}$ & Dermoid cysts \\
\hline Ovarian cyst & Ovarian cyst & $\begin{array}{l}\text { Broad ligament } \\
\text { cyst }\end{array}$ \\
\hline Ovarian cyst & Normal & Normal \\
\hline Ovarian cyst & $\begin{array}{l}\text { Left ovarian } \\
\text { cyst }\end{array}$ & No cyst \\
\hline $\begin{array}{l}\text { Pelvic } \\
\text { inflammatory } \\
\text { disease }\end{array}$ & Normal & $\begin{array}{l}\text { Bilateral } \\
\text { functional } \\
\text { ovarian cyst }\end{array}$ \\
\hline
\end{tabular}

9 cases were posted for scan and laparotomy and their clinical diagnosis, scan diagnosis and laparotomy confirmation was compared. Out of 9 cases, clinical diagnosis differed in all cases, thus giving zero percent of accuracy for clinical diagnosis.

Scan diagnosis matched with laparotomy confirmation in only $3(33.3 \%)$ of cases. One case which was labeled as normal was found to have bilateral functional ovarian cyst on laparotomy confirmation. One case which was labeled as left ovarian cyst was found to have no cyst on laparotomy confirmation. Thus, it is important to use laparoscopy/laparotomy method for final confirmation of diagnosis.

\section{DISCUSSION}

Ovarian cyst was the most common presentation which constituted more than half of the patients $(55.6 \%)$. The next most common presentation was fibroids which was present in $12(33.3 \%)$ of patients. While in the present study, only four patients presented with pelvic inflammatory disease. All patients i.e. 36 (100\%) had menorrhagia as the complaint of menstrual irregularity. Oligomenorrhea was seen in $4(11.1 \%)$ of patients. The most common presenting chief complaint of the patients in the department was pain abdomen in $10(27.8 \%)$ of cases followed by mass per abdomen and infertility in 9 (25\%) of cases. Remaining 8 (22.2\%) of cases presented with menstrual abnormalities. Out of 9 cases, clinical diagnosis differed in all cases, thus giving zero percent of accuracy for clinical diagnosis. Scan diagnosis matched with laparotomy confirmation in only 3 (33.3\%) of cases. One case which was labeled as normal was found to have bilateral functional ovarian cyst on laparotomy confirmation. One case which was labeled as left ovarian cyst was found to have no cyst on laparotomy confirmation.

Kilonzo A indicated that it is safe and feasible for gynecologic emergencies to carry out the laparoscopic surgery. They also added that there is a need for more research regarding the usefulness of laparoscopic surgery in late pregnancy for non-obstetric emergencies. ${ }^{4}$

Aulestia SN et al found that in one third of patients, the preoperative diagnosis differed from that of laparoscopic diagnosis. $^{1}$ They carried out therapeutic laparoscopic procedures in $82 \%$ of cases and reported that the results were satisfactory. They did not observe any morbidity and mortality in their study results. Thus, they concluded that laparoscopy was effective and safe as a diagnostic and treatment method in gynecologic emergencies.

Lopez Rivadeneyra E et al studied 78 cases. $^{6}$ They observed that ovarian cyst and ectopic pregnancy were the commonest presentation. They found abdominal pathology in $97.4 \%$ of cases. They reported that gynecological pathology was present in $98.6 \%$ of cases. In one fourth of cases, endoscopy was converted into laparotomy. This was due to massive hemo-peritoneum that occurred in tubal rupture of ectopic pregnancy cases. Thus, they concluded that in gynecological emergencies laparoscopy was very useful.

Otte WD et al studied 520 cases of acute abdomen. ${ }^{7}$ They noted that $35.2 \%$ of patients could have been treated by laparoscopic method. In their study, $24.8 \%$ of cases underwent laparotomy. They observed that the laparotomy was economical for the patients. Taylor EW et al in their two-year study included 19 women. ${ }^{8}$ They all were cases of acute abdomen with unknown cause. All of them have undergone diagnostic laparoscopy.

All women were premenopausal. It was found that laparoscopy was $100 \%$ accurate. 11 cases were of appendicitis, 5 cases were of pelvic inflammatory disease, 2 cases were of ovarian cyst, one case was of salpingo-oophorectomy. They concluded that laparoscopy was good accuracy. Faggi U et al noticed 
that laparoscopic approach was useful in preoperative diagnosis. ${ }^{9}$ It is also a very good surgical approach.

Tarraza HM et al evaluated one female patient. She presented with acute abdomen. Based on their experience, the author stated that in such situation, one should consider either gynecologic or surgical disorder in such women. ${ }^{10}$ They stated acute abdomen can be approached by using the laparoscopic method. They also agreed that certain conditions need laparotomy.

Schmidt-Matthiesen A et al cautioned that acute lower abdomen should be diagnosed as early as possible. ${ }^{11}$ Initially gynecological and surgical causes should be ruled out.

\section{CONCLUSION}

Thus, laparoscopy is a useful tool for diagnosis and therapeutic accuracy in gynecological disease in routine as well as in emergencies. It is safe, effective, less time consuming, economical and patient friendly.

Funding: No funding sources

Conflict of interest: None declared

Ethical approval: The study was approved by the Institutional Ethics Committee

\section{REFERENCES}

1. Aulestia SN, Cantele H, Leyba JL. Laparoscopic Diagnosis and Treatment in Gynecologic Emergencies. J Soc Laparoendoscopic Surgeons. 2003;7(3):239-42.

2. Agrusa A, Romano G, Di Buono G. Laparoscopic approach in abdominal emergencies: a 5-year experience at a single center. G Chir. 2012;33(1112):400-3.

3. Promecene PA. Laparoscopy in gynecologic emergencies. Surg Innovation. 2001;9(1):64-75.

4. Kilonzo A. The role of laparoscopy in the management of gynecologic surgical emergencies: A review of literature. World J Laparoscopic Surg. 2010;3(3):127-30.

5. Magos AL, Baumann R, Turnbull AC. Managing gynecologic emergencies with laparoscopy. Br Med J. 1989;299:371-4.

6. Rivadeneyra LE, Gurierrez Garcia V, Barron Vallejo J. Diagnostic and therapeutic usefulness of laparoscopic surgery in acute abdomen of gynecologic origin. Ginecol Obstet Mex. 1998;66:377-80.

7. Otte WD, Schneiders K. Value of laparoscopy in acute abdomen. Zentralbl Chir 2000;125(1):74-6.

8. Taylor EW, Kennedy CA, Dunham RH. Diagnostic laparoscopy in women with acute abdominal pain. Surg Laparosc Endosc. 1995;5(2):125-8.

9. Faggi U, Giovane A. Diagnostic laparoscopy in non traumatic abdominal emergencies] [Article in Italian. Minerva Chir. 2003;58(1):9-16.

10. Tarraza HM, Moore RD. Gynecologic causes of the acute abdomen and the acute abdomen in pregnancy. Surg Clin North Am. 1997;77(6):1371-94.

11. Schmidt-Mattiesen A, Schmidt-Matthiesen H. [Acute disease of the pelvis: differentiation between gynecologic and surgical cause. Geburtshilfe Frauenheilkd. 1993;53(11):754-9.

Cite this article as: Sitalakshmi V, Bansal A. Gynecological profile of patients undergoing laparoscopy/laparotomy in a tertiary care hospital. Int J Reprod Contracept Obstet Gynecol 2017;6:2475-8. 